\title{
Bioreducible Cross-Linked Nanoshell Enhances Gene Transfection of Polycation/DNA Polyplex In Vivo
}

Ji-Gang Piao, Shen-Gang Ding, Lu Yang, Ye-Zi You*

1. Materials. Acryloyl chloride (Sinopharm Chemical Reagent Co. Ltd., $\geq 97 \%$ ) was freshly distilled before use. Both 2-(2-methoxyethoxy)ethyl methacrylate $\left(\mathrm{MEO}_{2} \mathrm{MA}\right)$ (Sigma-Aldrich, 95\%) and oligo(ethylene glycol) methacrylate (OEGMA) (Sigma-Aldrich, 95\%) were purified by passing through a basic alumina column to remove the inhibitors. 2,2'-Azobisisobutyronitrile (AIBN, Sigma-Aldrich, 98\%) was re-crystallized twice from ethanol. Triethylamine (HPLC grade, $\geq 99.5 \%$ ) was purchased Aladdin. Absolute ethanol (AR, $\geq 99.7 \%$ ), dichloromethane (AR, $\geq 99.5 \%$ ), cystamine dihydrochloride ( $\geq 98 \%$ ), hydrofluoric acid (40 wt $\%)$, sodium methoxide solution in methanol $(25-28 \%)$ and sodium hydroxide (AR, $\geq 96.0 \%$ ) were purchased from Sinopharm Chemical Reagent Co. Ltd. (SCRC, China) and used as received. D,L-dithiothreitol (DTT, Sigma-Aldrich, $\geq 99.0 \%$ ) is used as received.

2. Characterizations. ${ }^{1} \mathrm{H}$ NMR spectra was recorded on a Bruker $\mathrm{AC} 400 \mathrm{MHz}$ NMR. $M_{\mathrm{n}}$ and PDI for the prepared polymers were measured by gel permeation chromatography (GPC) using DMF as the eluent and narrow polydispersity polystyrenes as the standards. TEM images were obtained using a JEM-2010 transmission electron microscope operating at $120 \mathrm{kV}$. FT-IR spectra were obtained on an EQUIVOX55 (Bruker). Zeta-potential measurements were conducted on dilute solution of nanoparticles at $25{ }^{\circ} \mathrm{C}$ using a Malvern Zetasizer 
Nano ZS90 instrument (Malvern Co.). G' and G” were conducted on a AR G2 (TA Co., USA) with a Peltier device for temperature control. The determination of hydrodynamic diameters was performed by dynamic light scattering using a Malvern Zetasizer Nano ZS90 instrument (Malvern Co.) equipped with a $4 \mathrm{~mW}$ He-Ne laser $(\lambda=633 \mathrm{~nm})$ at $90^{\circ}$ scattering angle. The well-known cumulant method was applied to analyze the DLS autocorrelation function. The hydrodynamic diameter $d_{h}$ was calculated using the Stokes-Einstein equation as $d_{h}$ $=\kappa_{\mathrm{B}} \mathrm{T} / 3 \pi \eta_{\mathrm{o}} \mathrm{D}$, where $\kappa_{\mathrm{B}}$ is the Boltzmann constant, $\mathrm{T}$ is the absolute temperature, $\eta_{\mathrm{o}}$ is the sample viscosity and D is the diffusion coefficient. Surface charge of complexes was also measured at $25{ }^{\circ} \mathrm{C}$ with the same instrument. Given values were the average of at least three runs.

3. Synthesis of $N, N^{\prime}$-Cystaminebisacrylamide (CBA). After the mixture of cysteamine hydrochloride $(11.6 \mathrm{~g}, 50 \mathrm{mmol})$ in water $(50 \mathrm{~mL})$ was cooled to $0^{\circ} \mathrm{C}$, acryloyl chloride $(9.30 \mathrm{~g}, 100 \mathrm{mmol})$ in $\mathrm{CH}_{2} \mathrm{Cl}_{2}(10.0 \mathrm{~mL})$ and aqueous $\mathrm{NaOH}$ solution $(1.0 \mathrm{M}, 100 \mathrm{~mL})$ were added simultaneously via separated addition 100 $\mathrm{mL}$ funnels in 1 hour at $0^{\circ} \mathrm{C}$, and the reaction mixture was stirred for another 2 hours at room temperature. Subsequently, the reaction mixture was washed three times with deionized water, and the white powders were collected by filtration, recrystallized twice from ethyl acetate. Yield is $58.0 \%$.

4. Synthesis of cumyl dithiobenzoate. Sodium methoxide $(\geq 50 \%$ solutions in methanol, $55.00 \mathrm{~g}, \sim 0.50 \mathrm{~mol})$, elemental sulfur $(16.0 \mathrm{~g}, 0.50 \mathrm{~mol})$ and anhydrous methanol $(160.00 \mathrm{~mL})$ were added to a $500 \mathrm{~mL}$, three-neck round-bottomed flask, 
followed by dropwise addition of benzyl chloride (31.50 g, $0.25 \mathrm{~mol})$ in $60 \mathrm{~min}$ at room temperature. The reaction mixture was then heated in an oil bath at $70{ }^{\circ} \mathrm{C}$ for $18 \mathrm{~h}$. After cooling to $5^{\circ} \mathrm{C}$ using an ice bath, the precipitated salt was removed by filtration, and then methanol was removed in vacuo. Water $(100 \mathrm{~mL})$ was added to the residue, and washed three times with diethyl ether. Diethyl ether and $1.0 \mathrm{M}$ $\mathrm{HCl}(250 \mathrm{~mL})$ were added, dithiobenzoic acid (DTBA) was extracted into the ether layer, and the ether layer was washed three times with water. Water $(200 \mathrm{~mL})$ and 1.0 $\mathrm{M} \mathrm{NaOH}(250 \mathrm{~mL})$ were added, and sodium dithiobenzoate was extracted into the aqueous layer and washed three times with diethyl ether. Then, diethyl ether and $1.0 \mathrm{M} \mathrm{HCl}(250 \mathrm{~mL})$ were added, DTBA was extracted into the ether layer, washed the ether layer with water three times, and dried by anhydrous $\mathrm{Na}_{2} \mathrm{SO}_{4}$, and DTBA was obtained via removing the residual ether. Subsequently, a mixture of DTBA (10.59 g), $\alpha$-methylstyrene (10.0 g) and carbon tetrachloride (40 $\mathrm{mL}$ ) was heated at $70^{\circ} \mathrm{C}$. The resultant mixture was reduced to an oil in vacuo, the product was purified by passing through a column chromatography with n-hexane as an eluent to give cumyl dithiobenzoate as a dark purple oil. The yield is $39.0 \%$. ${ }^{1} \mathrm{H}$ NMR $\left(300 \mathrm{MHz}, \mathrm{CDCl}_{3}\right): \delta 7.86(\mathrm{~m}, 2 \mathrm{H}), 7.20-7.60(\mathrm{~m}, 8 \mathrm{H}), 2.03(\mathrm{~s}, 6 \mathrm{H})$. 


\section{Synthesis of PEG-based branched polymer and the variation of}

transmittance of its polymer aqueous solution with temperature.

2-(2-Methoxyethoxy)ethyl methacrylate $\left(\mathrm{MEO}_{2} \mathrm{MA}\right.$, molecualr weight is 188 Da, 1.316 g, $7 \mathrm{mmol}$ ), oligo(ethylene glycol) methacrylate (OEGMA, molecular weight is $475 \mathrm{Da}, 1.425 \mathrm{~g}, 3 \mathrm{mmol}$ ), N,N'-cystaminebisacrylamide (CBA, $0.520 \mathrm{~g}$, 2 mmol), cumyldithiobenzoate (CBD, 0.0298 g. 0.109 mmol) and azobisisobutyronitrile $(0.0078 \mathrm{~g}, 0.047 \mathrm{mmol})$ were added in a polymerization tube with THF $(18.0 \mathrm{~mL})$. The reaction mixture was vacuum-sealed after degassing by three freeze-pump-thaw cycles, and placed in a $60{ }^{\circ} \mathrm{C}$ oil bath for 15 h. Subsequently, a PEG-based branched polymer was obtained by precipitating into an excess of hexane, and dried under vacuum. $M_{\mathrm{n}}$ is 48700 , and PDI is 1.9. The molar percentages of $\mathrm{MEO}_{2} \mathrm{MA}$, OEGMA and CBA in the polymer are $58.0 \%, 28.1 \%$ and $13.9 \%$, respectively. Its LCST is $45{ }^{\circ} \mathrm{C}$.
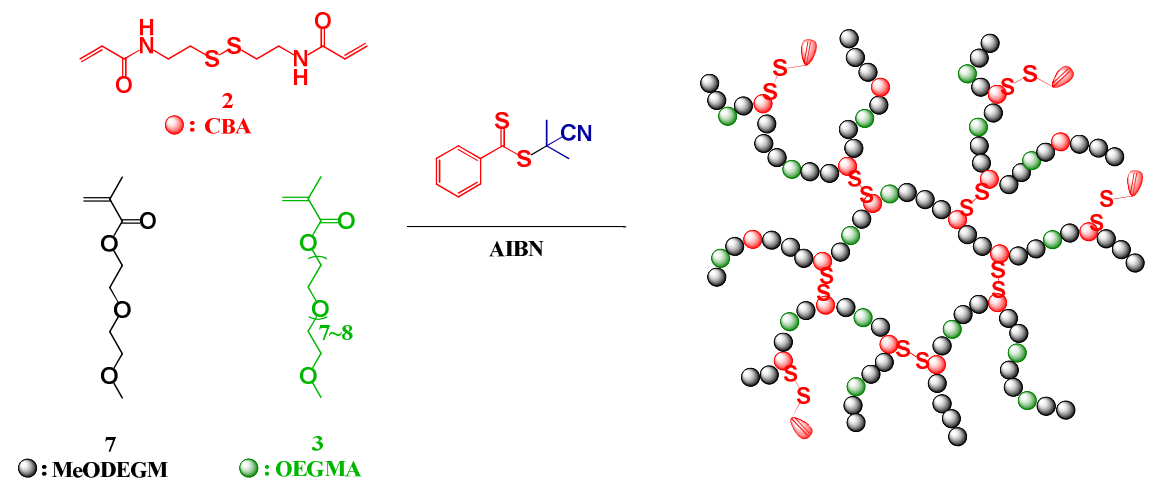

Scheme S1 Synthesis of PEG based branched polymer 

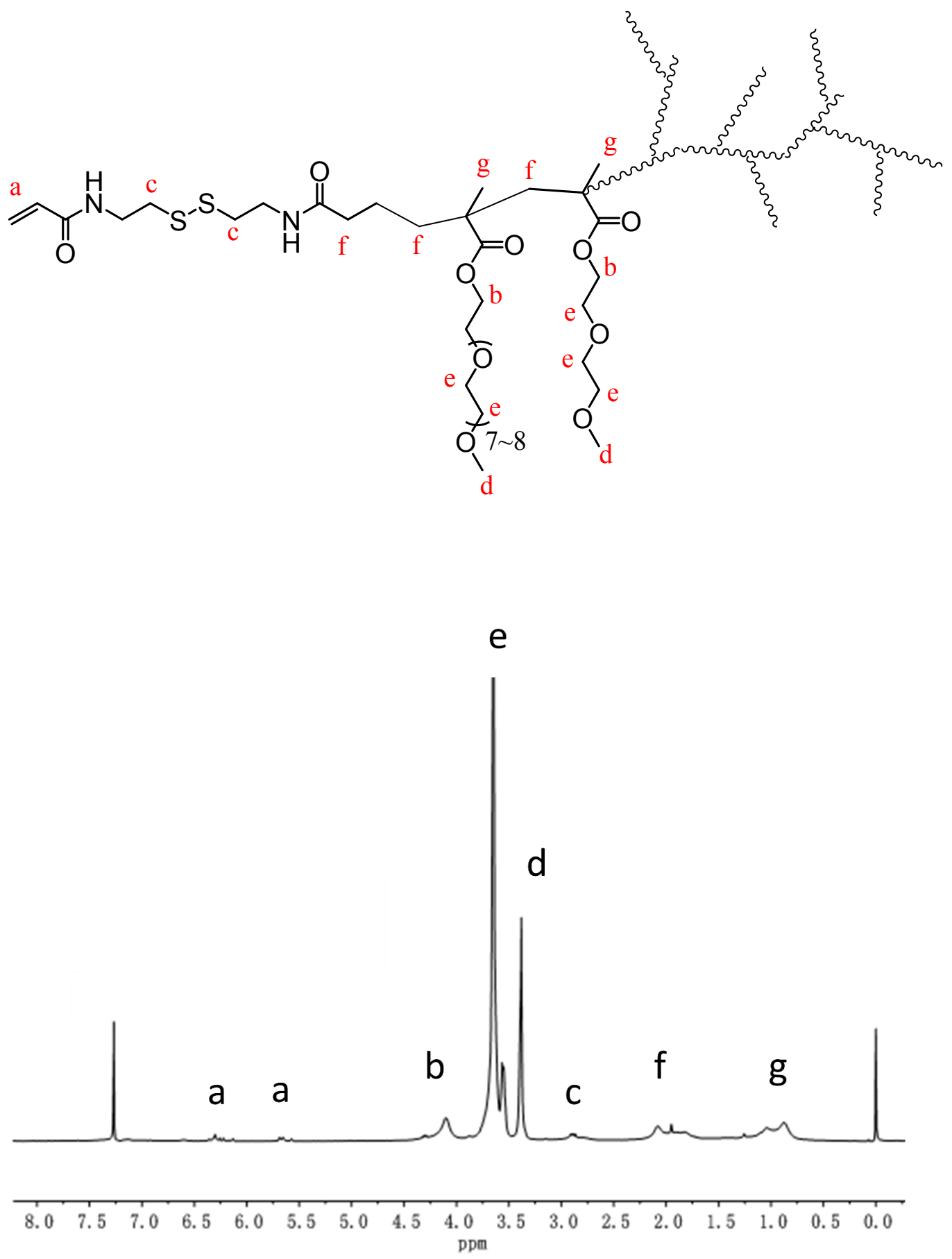

Fig. S1 1H NMR spectrum of PEG-based branched polymer 
The cloud point of PEG-based hyperbranched polymer solution in deionized water was measured using a Beckman DU 640 UV spectrophotometer equipped with a digital temperature controller. Transmittance of the copolymer aqueous solution at $550 \mathrm{~nm}$ was monitored as a function of temperature. The polymer concentrations tested were maintained at $3.0 \mathrm{mg} / \mathrm{mL}$.

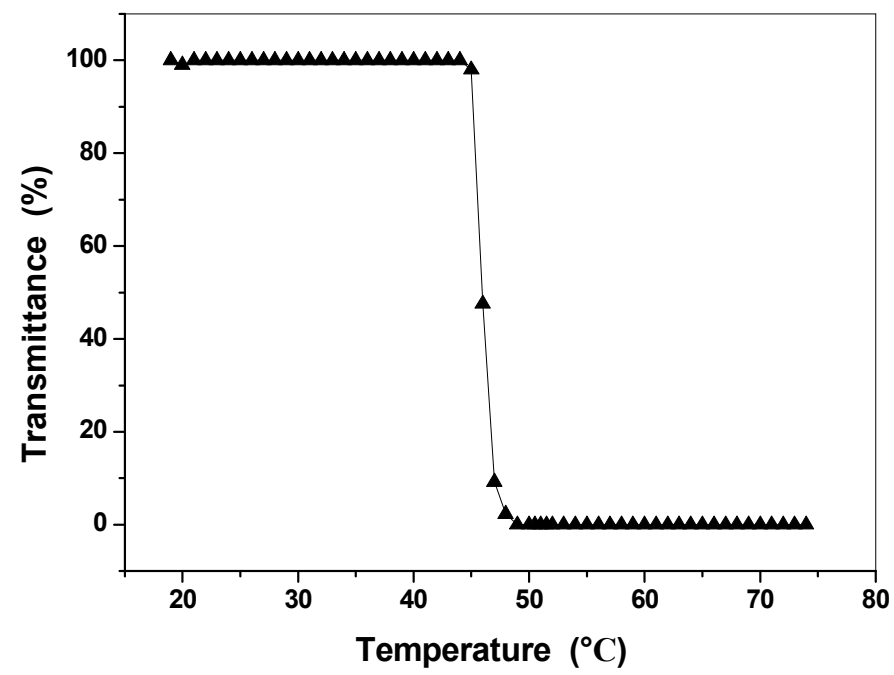

Fig. S2. The change of transimittance of PEG-based branched polymer aqeuous solution $(3.0 \mathrm{mg} / \mathrm{mL})$ with temperature

6. The variation of G' and G' for PEG-based branched polymer with time at 25 and $50^{\circ} \mathrm{C}$ 

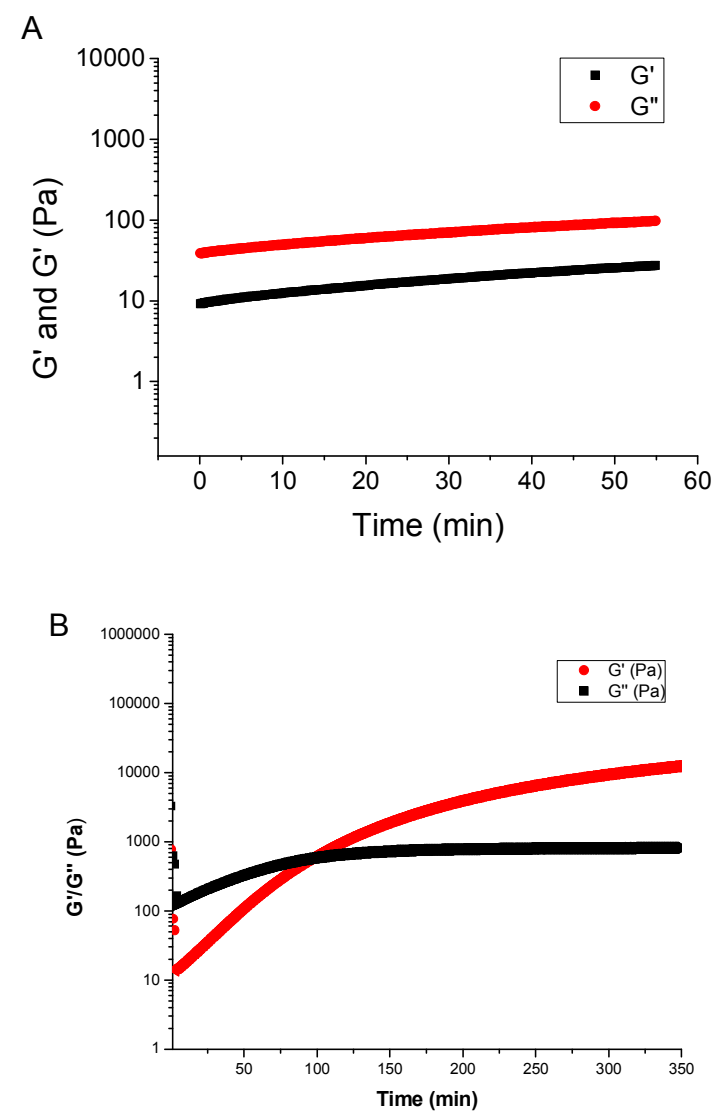

Fig. S3. The variation of G' and G" of PEG-based branched polymer with time at $25^{\circ} \mathrm{C}$ (A) and $50{ }^{\circ} \mathrm{C}(\mathrm{B})$.

There is cross-linking point of the curve of G' with time and the curve of G ', with time, indicating that the hyperbranched polymer undergoes self-crosslinking.

\section{Synthesis of PEI-g-PEG}

PEI (polyethylenimine) $\left(M_{\mathrm{w}}=25 \mathrm{k}, 0.5 \mathrm{~g}, 0.02 \mathrm{mM}\right)$ and PEGMA(poly(ethylene glycol) methyl ether acrylate) $\left(M_{\mathrm{n}}=480,0.1 \mathrm{~g}, 0.2 \mathrm{mM}\right)$ are separately dissolved in vials with anhydrous dichloromethane $(3 \mathrm{ml})$. Then, PEGDA solution is added to PEI solution with stirring. The vial is sealed with a solvent-resistant cap. The reaction is 
performed at $45{ }^{\circ} \mathrm{C}$ for $8 \mathrm{~h}$ with shaking. Then the polymer is precipitated into anhydrous diethyl ether and dissolved in water, subsequently, hydrochloric acid is added to adjust the $\mathrm{pH}$ to 4 . The acid polymer was precipitated into tetrahydrofuran (THF) and dried under vacuum. Each PEI macromolecule has 13 PEG chains.

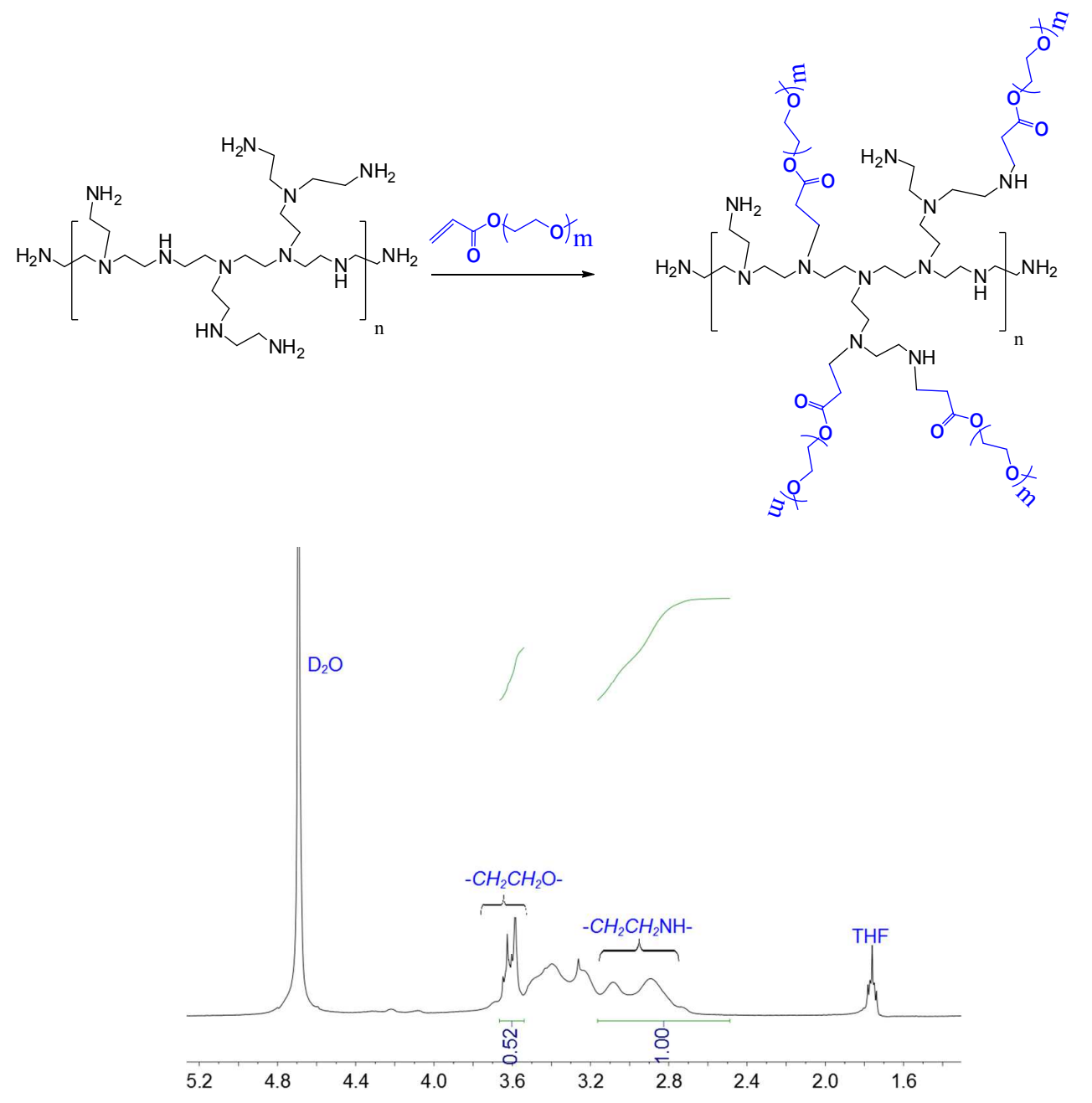

Fig. S4. ${ }^{1} \mathrm{H}$ NMR spectrum of PEI- $g$-PEG. 


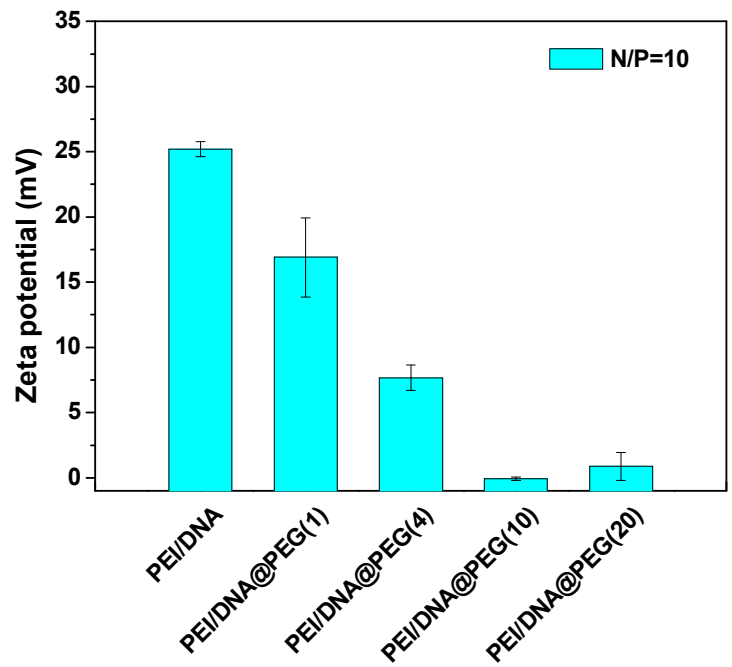

Fig. S5. Zeta potentials of PEI/DNA, PEI/DNA with a PEG-based nanoshell at PEG/DNA weight ratio of $1,4,10,20$.

8. Formation of PEG-g-PEI/DNA. DNA and PBS were combined to make the final concentration as $0.5 \mu \mathrm{g} /$ well. Then PEG-g-PEI was added to a final volume of 150 $\mu \mathrm{l} /$ well at $\mathrm{N}: \mathrm{P}$ of 10 , and incubation for $30 \mathrm{~min}$.

9. Formation of PEI/DNA + PEG. DNA and PBS were combined to make the final concentration as $0.5 \mu \mathrm{g} /$ well. Then PEI was added to a final volume of $150 \mu 1 /$ well at $\mathrm{N}$ : $\mathrm{P}$ of 10 , and incubation for $30 \mathrm{~min}$. PEG was added into the well to tune the PEG concentration to 10 times the DNA concentration.

10. Procedure for transfection efficiency measurement. The culture medium was discarded and cell lysate was harvested after incubation of cells for $30 \mathrm{~min}$ at room temperature in $100 \mu \mathrm{L}$ of cell lysis reagent buffer (Promega). To measure the luciferase content, $100 \mu \mathrm{L}$ of luciferase assay buffer (20 mM glycylglycine (pH 8), $1 \mathrm{mM} \mathrm{MgCl} 2,0.1 \mathrm{mM}$ EDTA, $3.5 \mathrm{mM}$ DTT, $0.5 \mathrm{mM}$ ATP, $0.27 \mathrm{mM}$ coenzyme) 
was automatically injected into $20 \mu \mathrm{L}$ of cell lysate, and the luminescence was integrated over $10 \mathrm{~s}$ using a single tube Sirius luminometer. Total cellular protein in the cell lysate was determined by the bicinchoninic acid (BCA) protein assay using a calibration curve constructed with standard bovine serum albumin solutions (Pierce). The luciferase transfection results are expressed in relative light units (RLU) per mg of cellular protein. Unless stated otherwise, the results are expressed as mean RLU mg ${ }^{-1}$ of protein \pm SD of triplicate experiments.

11. Linking RGD, mannose and folate onto the nanoshell. For example, small amout of RGD-NH2 was added to well and shake the plate for 30 min. RGD was linked onto the nanoshell via Michael reaction of anime and vinyl units.

a

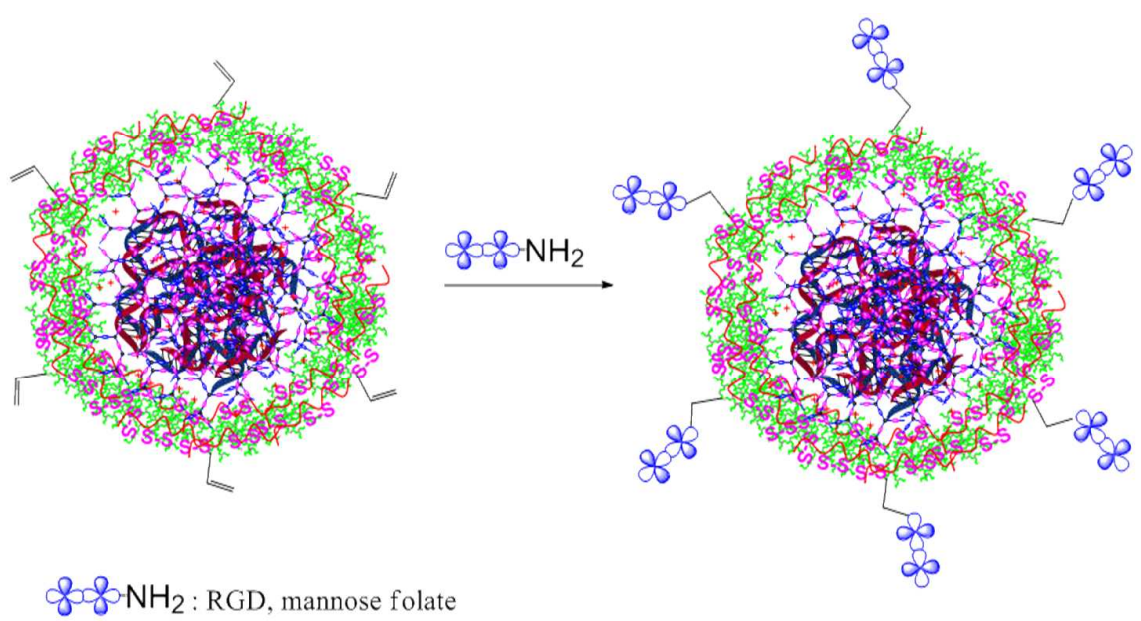


b

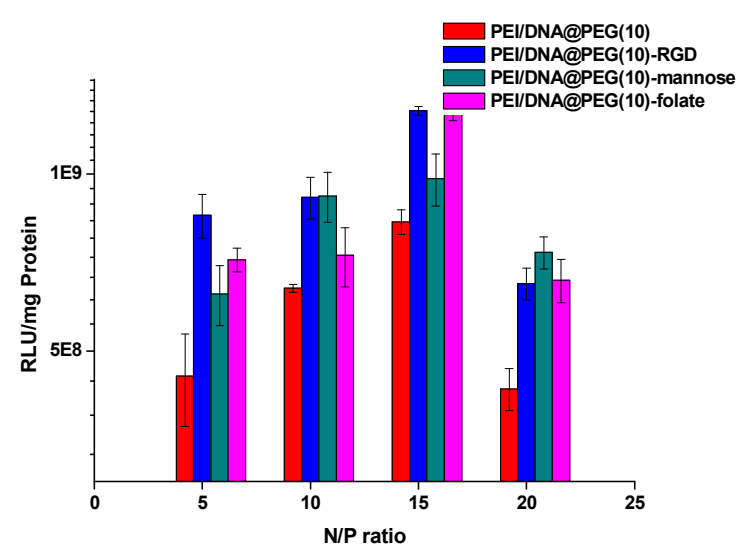

Fig. S6. (a) The outline for linking RGD, mannose and folate onto the nanoshell. (b) Gene transfection efficiency of PEI/DNA@PEG(10) with RGD, mannose or folate on the nanoshell in Hela cell in the presence $10 \%$ serum.

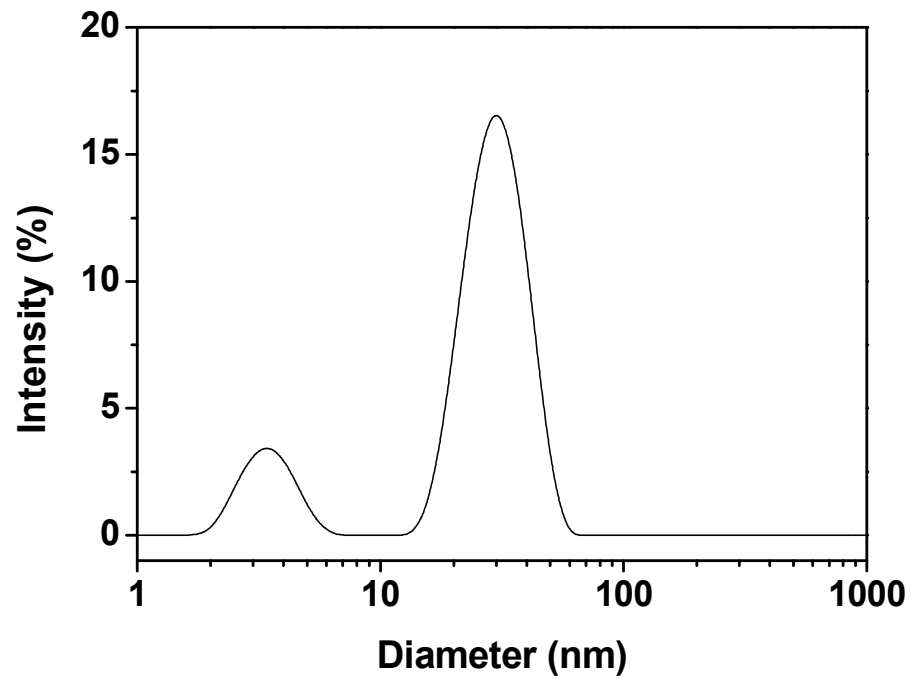

Figure S7. DLS results for just the branched PEG/PEI without the DNA as a control. 


\section{Synthesis of PEG-based branched polymer without disulfide bond.}

2-(2-Methoxyethoxy)ethyl methacrylate $\left(\mathrm{MEO}_{2} \mathrm{MA}\right.$, molecualr weight is 188 Da, $1.88 \mathrm{~g}, 10 \mathrm{mmol}$ ), $N, N^{\prime}$-methylenebisacrylamide (MBA, $0.310 \mathrm{~g}, 2 \mathrm{mmol}$ ), cumyldithiobenzoate (CBD, 0.0298 g. $0.109 \mathrm{mmol}$ ) and azobisisobutyronitrile $(0.0078 \mathrm{~g}, 0.047 \mathrm{mmol})$ were added in a polymerization tube with THF $(10.0 \mathrm{~mL})$. The reaction mixture was vacuum-sealed after degassing by three freeze-pump-thaw cycles, and placed in a $60{ }^{\circ} \mathrm{C}$ oil bath for $15 \mathrm{~h}$. Subsequently, a PEG-based branched polymer was obtained by precipitating into an excess of hexane, and dried under vacuum. $M_{\mathrm{n}}$ is 28700 , and PDI is 1.7 .

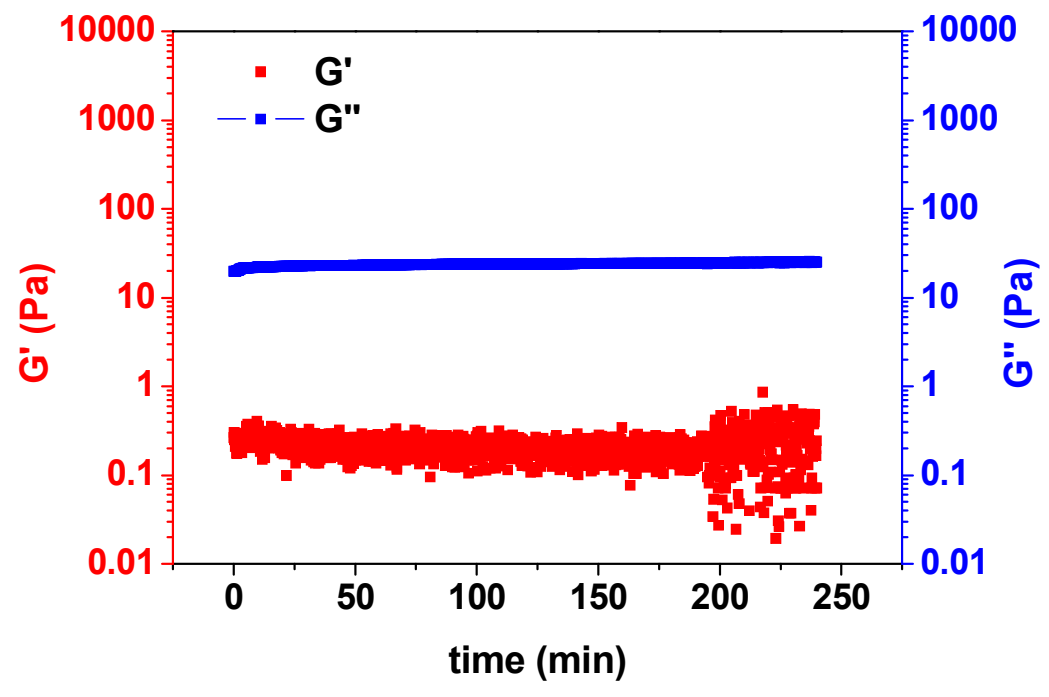

Fig. S8. The variation of G' and G" of PEG-based branched polymer (without disulfide bond ) with time at $50{ }^{\circ} \mathrm{C}$. 